\title{
Scanning Transmission Electron Microscopy Characterization of the Native Surfaces Oxides in High Density Ceramic Fuels
}

\author{
Philip D Edmondson ${ }^{*}, 1$, Quinlan B Smith ${ }^{1}$, Jesse W Werden ${ }^{1}$, Darren Skiff ${ }^{1}$, Chris Hobbs ${ }^{1}$, Joshua T \\ White $^{2}$, John T Dunwoody ${ }^{2}$, Kurt A Terrani ${ }^{1}$ and Andrew T Nelson ${ }^{1}$ \\ 1. Oak Ridge National Laboratory, Oak Ridge, TN, USA. \\ 2. Los Alamos National Laboratory, Los Alamos, NM, USA. \\ * Corresponding author: edmondsonpd@ornl.gov
}

Uranium-bearing ceramics that offer high heavy metal densities are of great interest as advanced fuels and are under current development. However, their basic structure and chemistry are much less understood when compared to the more established fuel systems, e.g. $\mathrm{UO}_{2}$. This lack of baseline data on the chemistry and structure of the unirradiated high density fuels poses problems for the interpretation of the microstructural and chemical evolution of the fuels during qualification of the out-of-pile performance as well as initial post irradiation examination using advanced characterization tools.

Several high-density fuel concepts are currently being developed, most notably those focused around the U-Si system in which multiple candidate fuel compounds are available. $\mathrm{U}_{3} \mathrm{Si}_{2} \mathrm{U}_{3} \mathrm{Si}_{2}, \mathrm{USi}$, and $\mathrm{U}_{3} \mathrm{Si}_{5}$ have received the most attention from the fuels community due to their individual properties and relevance to fabrication or thermodynamic assessments of the system. These compounds all offer improved thermal conductivity when compared to conventional oxide fuels; $\mathrm{U}_{3} \mathrm{Si}$ and $\mathrm{U}_{3} \mathrm{Si}_{2}$ also offer higher uranium density than $\mathrm{UO}_{2}$. There is also an interest in uranium mononitride (UN) as a high-performance fuel option for advanced reactor designs.

Of specific interest to these advanced fuels is the formation of the native oxide layer. The oxidation behavior of these advanced fuels is a significant unknown and is likely a key vulnerability of these systems. Whilst a detailed characterization of the materials exposed to high temperatures have been conducted, there has been little effort in the characterization of the native oxide in the as fabricated state. Knowledge in this area will likely have an impact on possible fabrication routes of these materials, along with potentially washout behavior.

Here we will present the initial results of the use of advanced microscopy techniques in the determination of the nature of the native oxide in a range of uranium silicides and uranium mononitride. In particular, a discussion will be made on the non-trivial preparation of such materials that have the propensity to readily oxidize under normal laboratory conditions. (room temperature and air pressure) Additionally, results of electron backscatter diffraction (EBSD - Figure 1) and scanning transmission electron microscopy combined with energy dispersive spectroscopy (STEM-EDS - Figure 2) will also be discussed and placed into context about advanced fuel fabrication methods. 


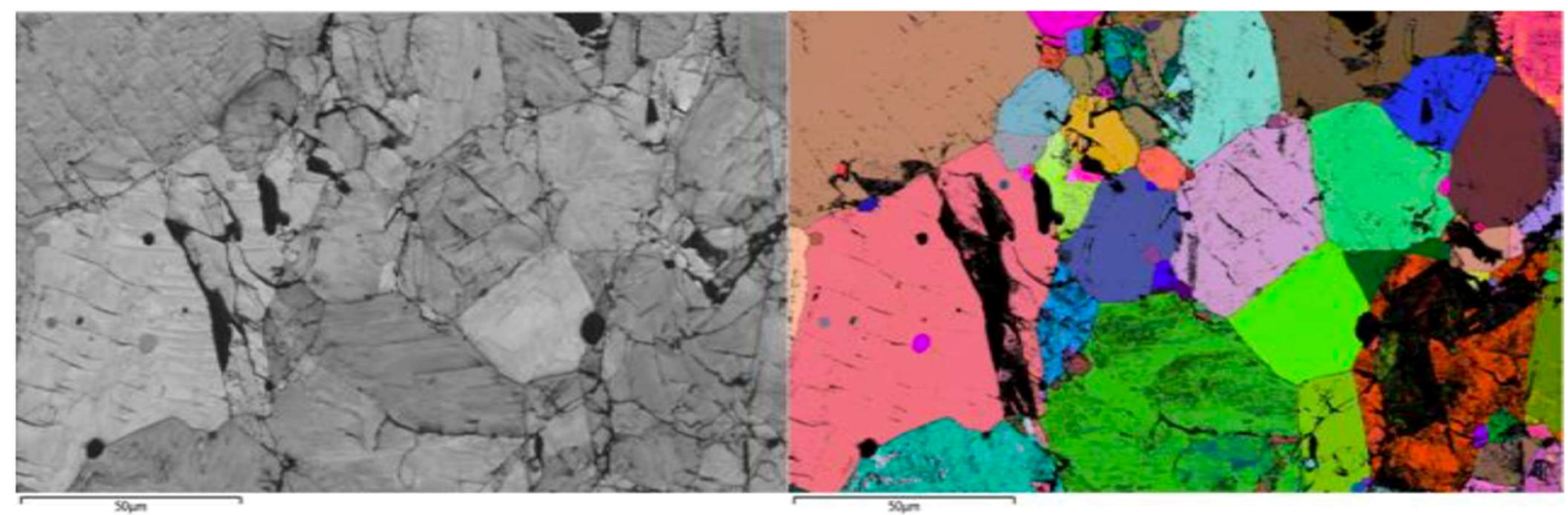

Figure 1. EBSD band contrast (left) and Euler angles (right) from a $\mathrm{U}_{3} \mathrm{Si}_{5}$ high density ceramic fuel specimen.

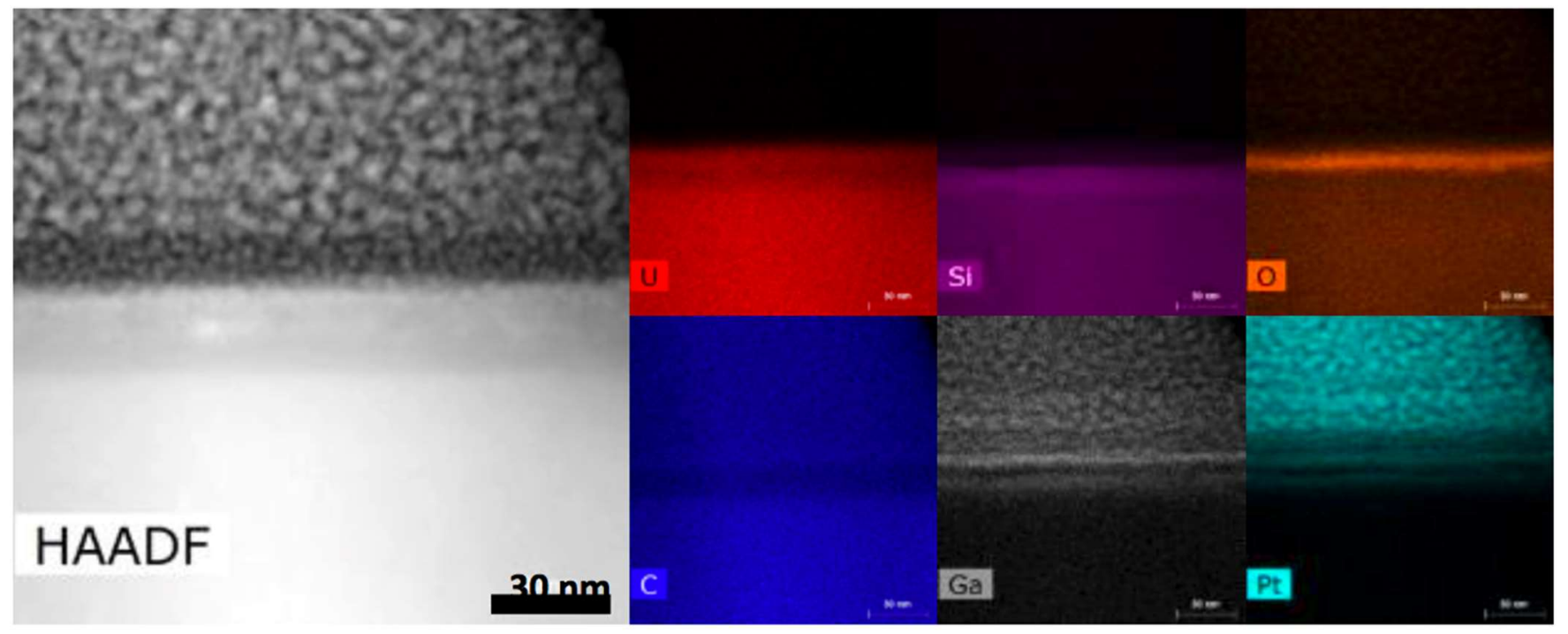

Figure 2. STEM-EDS maps for $\mathrm{U}_{3} \mathrm{Si}_{2}$. Note the presence of the protective $\mathrm{Pt}$ cap at the surface of the specimen. 